\title{
ANÁLISE DA SUSCETIBILIDADE E VULNERABILIDADE À EROSÃO HÍDRICA PELO PROCESSO ANALÍTICO HIERÁRQUICO (AHP)
}

\author{
ANALYSIS OF SUSCEPTIBILITY AND VULNERABILITY TO WATER EROSION BY \\ ANALYTIC HIERARCHY PROCESS (AHP)
}

\author{
Marianne Silva Santos, Paulo Sérgio de Rezende Nascimento
}

Departamento de Engenharia Ambiental da Universidade Federal de Sergipe - UFS

mariianne@outlook.com,psrn.geologia@gmail.com

Submissão: 27 de junho de 2020 Aceitação: 1 de dezembro de 2020

\section{Resumo}

A determinação da potencialidade à erosão hídrica é o ponto de partida para minimizar os processos de degradação do solo e a perda da biodiversidade. As geotecnologias apresentam-se como ferramentas de suporte no diagnóstico e prognóstico ambiental, a partir da análise espacial dos processos erosivos. Dessa forma, o objetivo deste estudo foi aplicar a análise multicriterial para determinar a suscetibilidade e vulnerabilidade à erosão hídrica da Bacia Hidrográfica do Rio São Francisco no estado de Sergipe. O principal procedimento empregado foi o Processo Analítico Hierárquico (AHP), cujos critérios utilizados foram: erodibilidade, erosividade, hipsometria, declividade e cobertura do solo. Os resultados obtidos foram um aumento expressivo das áreas que apresentaram suscetibilidade erosiva moderadamente baixa, moderadamente alta e alta. Por outro lado, as áreas com vulnerabilidade erosiva muito baixa e baixa foram maiores do que as áreas suscetíveis à erosão. Foi possível concluir que a Bacia Hidrográfica do Rio São Francisco apresentou, predominantemente, baixo potencial à vulnerabilidade erosiva em função das práticas adequadas de manejo nas áreas de pastagens. Entretanto, é fundamental a recomposição da vegetação ciliar e o reflorestamento dos biomas Caatinga e Mata Atlântica, visto que houve uma perda significativa da vegetação nativa.

Palavras-chave: Erosão do solo; conservação do solo; sistema de manejo do pastejo.

\section{Abstract}

Determining the potential for water erosion is the starting point for minimizing soil degradation processes and loss of biodiversity. Geotechnologies are presented as support tools in environmental diagnosis and prognosis based on the spatial analysis of erosive processes. Thus, the objective of this study was to apply multicriterial analysis to determine the susceptibility and vulnerability to water erosion in the São Francisco River Basin in the state of Sergipe. The main procedure used was the Analytic Hierarchy Process (AHP), whose criteria used were erodibility, erosivity, hypsometry, slope and soil cover. The results obtained were a significant increase in areas that presented moderately low, moderately high and high erosive susceptibility. In opposition, areas with very low and low erosive vulnerability were greater than areas susceptible to erosion. It was possible to conclude that the São Francisco River Basin presented, predominantly, low potential to erosive vulnerability due to the adequate management practices in the pasture areas. However, the restoration of riparian vegetation and the reforestation of the Caatinga and Atlantic Forest biomes are essential, since there was a significant loss of native vegetation.

Keywords: Soil erosion; soil conservation; grazing management system. 


\section{INTRODUÇÃO E FUNDAMENTAÇÃO TEÓRICA}

Para atender às demandas da sociedade, os recursos naturais vêm sendo constantemente explorados, desencadeando e acelerando desequilíbrios ambientais. Segundo Guerra e Cunha (2000), o uso inadequado dos recursos naturais, nas zonas urbana e rural, é a principal causa da degradação do meio ambiente. A degradação está associada aos impactos ambientais adversos, como a erosão e perda da fertilidade dos solos, assoreamento dos recursos hídricos superficiais, inundação das várzeas, escorregamento de encostas e perda da biodiversidade.

Segundo o relatório da FAO (2015), a erosão ocasiona perda de 25 a 40 bilhões de toneladas de solo por ano no mundo. O relatório aponta que a erosão em solo agrícola e de pastagem intensiva varia entre cem a mil vezes a taxa de erosão natural. Dessa forma, o processo erosivo intensificado pela atividade antrópica acarreta impactos ambientais, pois, além da perda do solo, o material erodido se depositará nos corpos d'água, provocando o assoreamento acelerado.

A erosão é o processo de desagregação, transporte e deposição das partículas do solo provocada por agentes hídrico e eólico (CUIABANO et al., 2017), cuja força motriz é a força da gravidade. Os fatores ambientais e antrópicos exercem influência na erosão dos solos, entretanto, ainda é um grande desafio determinar com precisão a interferência de cada um desses fatores na erosão e o efeito no sistema como um todo (SANTOS; GRIEBELER; DE OLIVEIRA, 2010). No Brasil, o tipo de erosão mais recorrente é a hídrica, decorrente da grande incidência de chuva, acelerando o processo e causando prejuízo tanto ao meio ambiente quanto à socioeconomia (PEREIRA et al., 2003). A erosão hídrica transporta sedimentos provocando o assoreamento, poluição e eutrofização dos corpos hídricos, principalmente devido ao uso de fertilizantes e agroquímicos.

De acordo com Brady (1989) e Hernani, Kurihara e Silva (1999), a erosão é o fenômeno mais destrutivo que afeta o solo em âmbito mundial, pois ao ocasionar a perda acelerada dos nutrientes e matéria orgânica, provoca o seu empobrecimento e a degradação do agroecossistema. Consequentemente, há redução significativa da produtividade das culturas e da capacidade de armazenar carbono, nutrientes e água. A água ao ser escoada, não pode ser aproveitada em períodos de seca, acarretando queda na produtividade. Dessa forma, os impactos ambientais da erosão do solo ocasionam impactos socioeconômicos, que exercem pressão sobre o meio ambiente.

Há dois tipos de erosão provocada pelo escoamento da água da chuva: a erosão laminar e a erosão linear. A erosão laminar é caracterizada pelo regime difuso (não concentrado) e uniforme do escoamento superficial, resultando na remoção homogênea das camadas superficiais do solo (MAGALHÃES, 2001), diminuindo a sua fertilidade (GOBBI et al., 2011). Já a erosão linear é proveniente da concentração do fluxo superficial das águas, resultando em incisões na superfície do terreno, iniciando como sulcos e progredindo para ravinas e voçorocas (ALMEIDA FILHO, 2015; SALOMÃO, 1999).

Os processos erosivos, segundo Guerra e Cunha (2000), são controlados pela erosividade da chuva, erodibilidade dos solos/rochas, cobertura vegetal e características das vertentes. Esses fatores, associados ou não, definem a suscetibilidade de ocorrência da erosão natural ou geológica. Já a vulnerabilidade está associada às práticas humanas que intensificam a erosão. Nesse sentido, o desmatamento da vegetação nativa para a implantação da agricultura extensiva, pecuária intensiva, exploração mineral e expansão urbana, é o principal desencadeador da erosão acelerada ou antrópica (NASCIMENTO, 2004).

A erosividade, segundo Wischmeier e Smith (1958), é a capacidade da chuva em causar erosão no solo, e é atribuída à duração e frequência da chuva, quanto mais longa e frequente for, maiores serão os danos. Bertoni e Lombardi Neto (2010) expressam a relação entre a velocidade da água e o seu poder erosivo através da Equação (1):

$$
E c=\frac{m V^{2}}{2}
$$

onde: $\mathrm{Ec}=$ energia cinética; $\mathrm{m}=$ massa de água incidente; e $\mathrm{V}=$ velocidade terminal da gota durante o impacto.

A erodibilidade é o grau de resistência do solo/rocha em erodir, identificada pela interação entre as características físicas (textura, estrutura, 
permeabilidade e densidade), químicas, mineralógicas e biológicas do solo (CORRECHEL, 2003), tornando-o mais propenso à erosão do que outro a depender de tais propriedades. Outro fator importante da suscetibilidade dos solos a processos erosivos é a topografia, principalmente em função da declividade e do comprimento das encostas (STEPHAN, 2010). Em locais onde o terreno é plano ou possui pequenas elevações, a velocidade do escoamento é menor, prevalecendo a infiltração da água no solo, em oposição aos maiores declives cuja velocidade do escoamento é maior (WEILL; PIRES NETO, 2007). O mesmo acontece para o comprimento da encosta; quanto maior for, mais alta será a velocidade do escoamento, favorecendo os processos erosivos. A perda de solo está relacionada com o declive do terreno, expressa por Bertoni e Lombardi Neto (2010) por meio da Equação (2):

$$
T=0,145 D 1,18
$$

onde: $\mathrm{T}$ = perda de solo em quilograma/unidade de largura/unidade de comprimento; 0,145= constante de variação; e $D=$ grau de declive do terreno, em porcentagem.

A vulnerabilidade à erosão é decorrente das atividades antrópicas e está condicionada aos fatores de cobertura vegetal e uso do solo (SCOLFORO; OLIVEIRA; CARVALHO, 2008). A vegetação é um dos principais fatores que protegem o solo dos agentes erosivos. De acordo com Almeida Filho (2015), a cobertura vegetal minimiza o impacto da gota de chuva (splash), evitando a desagregação de partículas do solo, diminui a velocidade do escoamento superficial e aumenta a porosidade através de suas raízes. Dessa forma, áreas com solo exposto aumentam a vulnerabilidade à erosão do terreno, e a exploração dos recursos naturais, sem práticas conservacionistas ou inadequadas de uso e manejo do solo, intensifica o processo erosivo (PEREIRA; SOUZA; CAMPOS, 2002).

O geoprocessamento é um conjunto de técnicas matemáticas e computacionais que permite manipular e analisar dados georreferenciados, resultando em modelagens diagnósticas e prognósticas do ambiente natural e antropizado (FITZ, 2008). Além disso, possibilita a integração de mapas temáticos, o que torna uma ferramenta essencial para a elaboração de estudos holísticos do ambiente (COELHO, 2009). Assim, as técnicas de geoprocessamento são ferramentas essenciais para análise da suscetibilidade e vulnerabilidade à erosão do solo, principalmente, de grandes áreas.

A análise da suscetibilidade e vulnerabilidade erosiva é executada por Sistema de Informação Geográfica (SIG), o qual integra dados, metodologias, equipamentos e pessoas com o objetivo de coletar, armazenar, recuperar, manipular, visualizar e analisar dados espacialmente georreferenciados a um sistema de coordenadas conhecido (SILVA, 2003). A partir dos SIGs, é possível produzir mapas temáticos com maior rapidez, precisão, baixos custos e com facilidade de atualização constante (NASCIMENTO; GARCIA, 2004; LONGLEY et al., 2013). A geração de mapas pode ser realizada pela compilação de mapas secundários, interpretação visual e automática de imagens de satélite e álgebra de mapas (MIRANDA, 2005).

A integração automática de mapas temáticos é fundamental para a gestão ambiental dos processos erosivos em uma bacia hidrográfica (NASCIMENTO, 2004). De acordo com Câmara (1995), as informações espaciais numa única base de dados possibilitam combinar geoinformações através de algoritmos de manipulação e análise. Nascimento e Petta (2008) destacam a Álgebra de Mapas (AM) para obter produtos cartográficos de suscetibilidade e vulnerabilidade erosiva. São procedimentos de análise espacial que produz novos dados, a partir de funções de manipulação aplicadas a um ou mais mapas (Equação 3).

$\mathrm{AM}=(\mathrm{P} 1 \times \mathrm{C} 1) \times(\mathrm{P} 2 \times \mathrm{C} 2) \times(\mathrm{P} 3 \times \mathrm{C} 3) \times(\mathrm{P} 4 \times \mathrm{C} 4)$

onde: $\mathrm{Pi}=$ Peso do critério de possibilidade "i" e $\mathrm{Ci}=$ Critério de possibilidade "i".

Outra possibilidade dos SIGs é a implementação de métodos que auxiliam na tomada de decisão por modelagem matemática, para comparar cenários e alternativas, de modo a apresentar soluções adequadas aos órgãos competentes (SILVA; BELDERRAIN, 2005). Segundo Gdoura, Anane e Jellali (2014), um dos poucos métodos de tomada de decisão que podem ser facilmente integrados com um SIG é o Processo de Análise Hierárquica (AHP). Esse processo de análise possui elementos capazes 
de avaliar as potencialidades ou restrições inerentes ao processo decisório, influenciando positivamente na tomada de ações (REZENDE; MARQUES; OLIVEIRA, 2017; PIMENTA et al., 2019).

O método AHP consiste na criação de uma ordenação de decisão composta por níveis hierárquicos, os quais permitem uma visão global das relações inerentes ao processo (SAATY, 2008). Para estabelecer a importância relativa de cada fator da hierarquia, são elaboradas matrizes de comparação para cada nível, em que os resultados das matrizes são ponderados entre si (SILVA; NUNES, 2009). A ponderação é feita para cada critério, por meio de comparações de pares, usando a escala de Saaty de números absolutos, em que se atribui valores numéricos tanto quantitativos como qualitativos aos julgamentos (DIAS; SILVA; BARROS, 2014).

Pinese Júnior e Rodrigues (2012) e Ribeiro et al. (2016) destacam a relevância da utilização do método AHP como suporte à tomada de decisão, com múltiplos critérios com variáveis hierárquicas de solução, em bacias hidrográficas. A bacia hidrográfica é uma unidade territorial de planejamento ambiental, que possui características essenciais para a integração multidisciplinar entre diferentes sistemas de gerenciamento, estudo e atividade ambiental (BERNARDI et al., 2012). De acordo com Albuquerque (2013), diversos pesquisadores relacionam a bacia hidrográfica como uma unidade natural da superfície terrestre, na qual é possível avaliar as inter-relações existentes entre os elementos da paisagem e os processos que atuam na sua estruturação, como a erosão hídrica do solo.

As intervenções humanas na Bacia Hidrográfica do Rio São Francisco aceleram os processos erosivos e o assoreamento do canal fluvial. Segundo Medeiros et al. (2007), o valor de material particulado em suspensão transportado pelo rio São Francisco era de $69 \times 10^{5}$ t/ano entre 1938 e 1973. Após a construção de 33 barragens, sendo nove delas no curso do rio, esse valor foi reduzido para $2,28 \times 10^{5}$ t/ano, impedindo a transferência dos sedimentos para o mar. Em decorrência deste processo, a região do Baixo São Francisco sergipano vem sofrendo vários impactos ambientais nas últimas décadas, destacando a destruição do povoado do Cabeço, que foi inundado pelo mar. Carvalho e Fontes (2006) destacam também os impactos ambientais, econômicos e sociais em função da perda de biodiversidade na região.

Diante dos impactos ocasionados pela erosão do solo, nota-se a importância de se realizar uma análise das áreas que estão suscetíveis e vulneráveis a esses processos, através das ferramentas de geoprocessamento. Este estudo serve também de subsídio para a tomada de ações que visem minimizar as adversidades dos impactos nas esferas ambientais, sociais e econômicas.

Posto isso, o presente trabalho visou delimitar as áreas suscetíveis e vulneráveis aos processos erosivos da Bacia Hidrográfica do Rio São Francisco (BHRSF) no estado de Sergipe, por meio de técnicas de geoprocessamento. Para atingir o objetivo geral, os mapas de declividade, hipsometria, erodibilidade, erosividade e cobertura do solo foram compilados, gerados e integrados a fim de obter os parâmetros para espacialização e hierarquização da suscetibilidade e vulnerabilidade erosiva hídrica. Desta forma, foi confeccionada uma base cartográfica de dados geoespaciais, visando contribuir para estudos futuros e para auxiliar na tomada de ações mitigadoras necessárias à minimização dos impactos ambientais sociais e econômicos oriundos da erosão do solo.

\section{METODOLOGIA}

A área de estudo compreende a Bacia Hidrográfica do Rio São Francisco no estado de Sergipe, à margem esquerda da foz do seu rio principal (Figura 1), e está delimitada pelas coordenadas geográficas 3800'03" e 3623'56" de longitude Oeste, e 930'59" e 10ํㅜㄴ'10" de latitude Sul. Abrange 27 munícipios, totalizando uma área de $7.345 \mathrm{~km}^{2}$, o que equivale a $33,5 \%$ do território estadual.

Os materiais utilizados foram: dados Shuttle Radar Topography Mission (SRTM), com resolução espacial de 30 metros do Projeto Topodata, disponibilizados pelo Instituto Nacional de Pesquisas Espaciais (INPE, 2011); dados de hidrografia, isoietas e uso da terra do Atlas Digital sobre Recursos Hídricos de Sergipe (SEMARH, 2013); e o programa de geoprocessamento QGIS, versão 2.14.

Inicialmente, os dados de interesse foram importados para o QGIS, no qual foram confeccionados os mapas de declividade, hipsometria, erosividade, erodibilidade e 
cobertura do solo. Estes mapas foram reprojetados automaticamente para o Sistema de Projeção UTM - Universal Transversa de Mercator, Datum Sirgas 2000 e Zona 24S.

Os mapas hipsométrico e declividade foram confeccionados a partir dos dados SRTM, cujos valores de elevação do terreno foram agrupados em classes com intervalo altimétrico de $100 \mathrm{~m}$ e as classes de declividade estabelecidas de acordo com a classificação proposta pela EMBRAPA (1999), que relaciona a morfometria com a morfografia do relevo. Os parâmetros morfométricos descrevem o relevo quanto aos seus aspectos quantitativos, enquanto os parâmetros morfográficos correspondem à forma do relevo (Tabela 1).

Figura 1: Mapa de localização e acesso da área de estudo

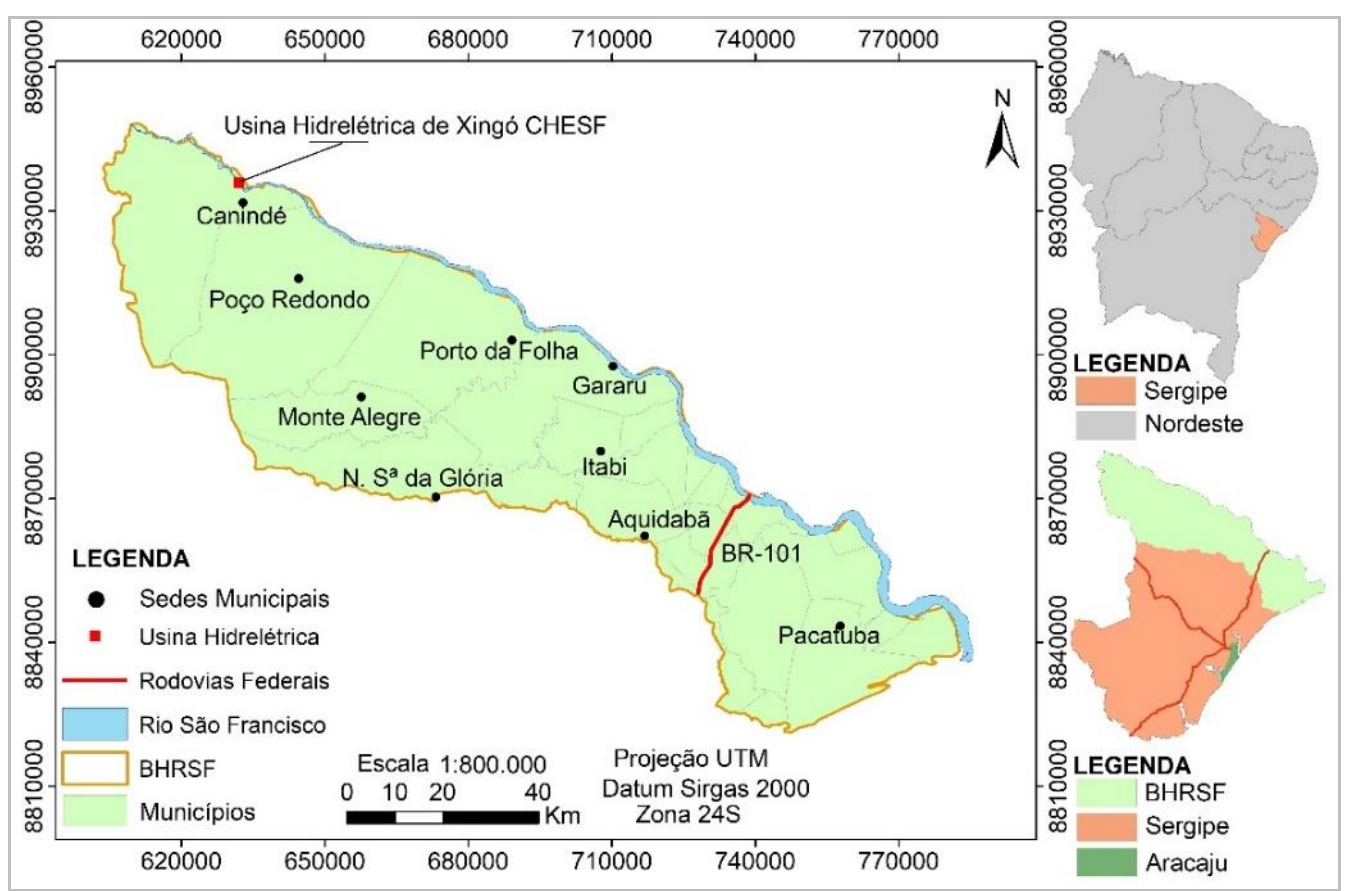

Fonte: Os autores (2020).

Tabela 1: Classes de declividade e as formas de relevo da BHRSF

\begin{tabular}{cc}
\hline Declividade (\%) & Relevo \\
\hline $0-3$ & Plano \\
\hline $3-8$ & Suave Ondulado \\
\hline $8-20$ & Ondulado \\
\hline $20-45$ & Forte Ondulado \\
\hline $45-75$ & Montanhoso \\
\hline$>75$ & Forte Montanhoso \\
\hline
\end{tabular}

Fonte: Adaptada de Embrapa (1999).

O mapa de erosividade da chuva foi obtido com os dados da precipitação média anual da bacia, disponibilizados pelo atlas supracitado e reclassificado em seis intervalos de classes. Confeccionou-se o mapa de erodibilidade pelo Interpolador de Kernel, com função quártica, em que as linhas de drenagem da bacia foram transformadas em uma malha pontos. A densidade de drenagem foi calculada com base na quantidade de número de pontos representativos de cada linha de drenagem. Dessa forma, a partir do grau de dissecação de relevo (ROSS, 1994), é possível definir as classes de erodibilidade como muito baixa, baixa, moderadamente baixa, moderadamente alta, alta e muito alta.

O mapa de cobertura do solo foi compilado do atlas supracitado e realizou-se uma 
associação das classes com características semelhantes, a partir da tabela de atributos e das características das classes temáticas. Este processo teve como objetivo deixar a imagem visualmente organizada e com informações compreensíveis, resultando num mapa reclassificado em: floresta, dunas, pastagem, cultivo agrícola, corpos d'água e áreas degradadas.

Após confeccionar os mapas, efetuou-se a atribuição de peso a cada classe temática de acordo com o seu grau de importância quanto à suscetibilidade e à vulnerabilidade erosiva. As ponderações foram feitas a partir da metodologia apresentada por Crepani et al. (2001). Esses autores atribuíram valores entre 1,0 e 3,0, preconizados por Tricart (1977), em função das condições predominantes de pedogênese e morfogênese. Os valores próximos a 1,0 estão associados à pedogênese, que são as unidades de paisagem consideradas estáveis e com equilíbrio dinâmico, 2,0 são atribuídas a condições intermediárias (intergrades), e 3,0 estão associados à morfogênese, que apresenta condições instáveis e predominância de características intrínsecas desencadeadoras de processos erosivos naturais ou geológicos.

Os pesos para cada classe foram distribuídos em cinco intervalos iguais, resultando num quintil. O quintil é um método estatístico de medida separatriz que permite cada classe ficar com $20 \%$ de seus elementos, de forma que a mediana esteja localizada no centro (NACHETTI; PINTO, 2007; RIBEIRO, 2015). Assim, os valores estabelecidos para cada classe temática encontram-se nas Tabelas 2 e 3.

Tabela 2: Pesos para as classes de declividade, hipsometria, erodibilidade e Erosividade

\begin{tabular}{ccccc}
\hline Pesos & Declividade & Hipsometria & Erodibilidade & Precipitação \\
\hline 1 & $0-3 \%$ & $<100 \mathrm{~m}$ & Muito Baixa & $600-730 \mathrm{~mm}$ \\
\hline 1,4 & $3-8 \%$ & $100-200 \mathrm{~m}$ & Baixa & $730-890 \mathrm{~mm}$ \\
\hline 1,8 & $8-20 \%$ & $200-300 \mathrm{~m}$ & Moderadamente baixa & $890-1020 \mathrm{~mm}$ \\
\hline 2,2 & $20-45 \%$ & $300-400 \mathrm{~m}$ & Moderadamente Alta & $1020-1050 \mathrm{~mm}$ \\
\hline 2,6 & $45-75 \%$ & $400-500 \mathrm{~m}$ & Alta & $1050-1280 \mathrm{~mm}$ \\
\hline 3 & $>75 \%$ & $>500 \mathrm{~m}$ & Muito Alta & $1280-1400 \mathrm{~mm}$ \\
\hline
\end{tabular}

Fonte: Os autores (2020).

Tabela 3: Pesos correspondentes às classes
de cobertura do solo
\begin{tabular}{cc}
\hline Pesos & Uso do solo \\
\hline 1 & Floresta \\
\hline 1,4 & Dunas \\
\hline 1,8 & Pastagem \\
\hline 2,2 & Cultivo agrícola \\
\hline 2,6 & Corpos d'água \\
\hline 3 & Áreas degradadas
\end{tabular}

Fonte: Os autores (2020).

Após a elaboração dos mapas temáticos com suas respectivas classes, determinou-se a importância relativa entre os fatores de declividade, hipsometria, erodibilidade e erosividade. Para isso, foi utilizado o Processo de Análise Hierárquica (AHP), que é um método empregado para auxiliar a tomada de decisões complexas. Construiu-se uma matriz quadrada de comparação pareada, estabelecendo a hierarquia de menos suscetível para mais suscetível. Nesta matriz, cada variável da coluna esquerda teve dominância em relação à variável da linha do topo (SAATY, 1994) (Tabela 4). Os valores da diagonal são unitários, pois uma variável comparada a ela mesma é igualmente importante (SANTOS; LOUZADA; EUGÊNIO, 2010).

Estabelecidos os pesos de cada variável, verificou-se o autovalor máximo, $\lambda_{\operatorname{máx}}$ e a razão de consistência. $O$ autovalor máximo é calculado pela multiplicação da matriz de comparação pelo vetor coluna $\mathrm{w}$, seguido da divisão desse novo vetor encontrado, Aw, pelo primeiro vetor $w$ 
(Equação 4).

$$
\text { גmåx }=\frac{1}{n} \Sigma \frac{A w}{w}
$$

A partir da divisão do índice de consistência (IC) pela inconsistência aleatória média (IAM) (Equação 5), calcula-se a razão de consistência (RC) (Equação 6).

$$
I C=\frac{\lambda m a ̊ x-n}{n-1}
$$

$$
R C=\frac{I C}{I R}
$$

De acordo com Saaty (1994), o resultado da razão deve apresentar valor menor que 0,10 e o valor do $\lambda_{\text {máx }}$ deve estar próximo do número de variáveis utilizadas para que haja consistência dos dados. Dessa forma, ao aplicar o método AHP, obteve-se o resultado de 0,046 para a razão de consistência, e 4,123 para o $\lambda_{\text {máx. }}$ A partir do cálculo da matriz, geraram-se os pesos estatísticos de cada variável, utilizados para a confecção do mapa de suscetibilidade erosiva (Tabela 5).

Tabela 4: Matriz quadrada de comparação pareada

\begin{tabular}{ccccc}
\hline Variáveis & Erosividade & Erodibilidade & Hipsometria & Declividade \\
\hline Erosividade & 1 & $1 / 3$ & $1 / 5$ & $1 / 7$ \\
\hline Erodibilidade & 3 & 1 & $1 / 3$ & $1 / 5$ \\
\hline Hipsometria & 5 & 3 & 1 & $1 / 3$ \\
\hline Declividade & 7 & 5 & 3 & 1 \\
\hline Fonte: Os autores (2020). & & &
\end{tabular}

Tabela 5: Pesos das variáveis utilizadas na geração do mapa de suscetibilidade à erosão

\begin{tabular}{ll}
\hline \multicolumn{1}{c}{ Mapa } & Pesos \\
\hline Erosividade & 0,057 \\
\hline Erodibilidade & 0,122 \\
\hline Hipsometria & 0,264 \\
\hline Declividade & 0,558 \\
\hline Fonte: Os autores (2020).
\end{tabular}

A declividade tem influência fundamental no aumento da velocidade do escoamento superficial, uma vez que quanto maior o declive, maior a energia cinética da água da chuva e, consequentemente, maior a suscetibilidade aos processos erosivos, sendo, por essa razão, 0 critério de maior importância na hierarquia.

A erosividade, por sua vez, teve menor importância em função da variabilidade climática ao longo da bacia, apresentando, na região de estudo, longos períodos de estiagem. No estudo feito por Rocha (2009), foi sugestionado que as taxas de erosão medidas na bacia não estão relacionadas às precipitações, mas ao aumento da vazão do rio, decorrente do aumento da precipitação no Alto e Médio São Francisco.

A atribuição dos pesos para o mapa de vulnerabilidade foi baseada no empirismo (Tabela 6), partindo da compreensão das características do ambiente alterado pelas ações antrópicas e pela síntese das informações pesquisadas acerca da influência negativa do homem na BHRSF.

Tabela 6: Pesos das variáveis utilizadas na geração do mapa de à erosão

\begin{tabular}{cc}
\hline Mapa & Pesos \\
\hline Suscetibilidade erosiva & 1,8 \\
\hline Cobertura do solo & 3,0
\end{tabular}

Fonte: Os autores (2020). 
Com as variáveis ponderadas, foi realizada a álgebra dos mapas de declividade (D), hipsometria $(H)$, erodibilidade do solo $(K)$ e erosividade da chuva (R) (Equação 7):

$S E=(R x 0,057) x(K x 0,122) x(H x 0,264) x(D x 0,558)$

Obteve-se o mapa de vulnerabilidade à erosão (VE) a partir da integração dos mapas de suscetibilidade erosiva (SE) e cobertura do solo (CS) (Equação 8).

$$
V E=(S E x 1,8) x(C S x 3,0)
$$

Estas operações resultaram nos mapas de suscetibilidade e vulnerabilidade aos processos erosivos, objeto de estudo, classificados em muito baixa, baixa, moderadamente baixa, moderadamente alta, alta e muito alta.

\section{RESULTADOS, ANÁLISE E DISCUSSÃO}

O mapa das classes de declividade (Figura 2) representa a morfometria da BHRSF, e retrata os processos geológicos exógenos à luz da morfogênese e pedogênese. Nesta, prevalece a formação do solo e naquela, a do relevo, indicando, de acordo com Tricart (1977), a estabilidade e instabilidade do terreno frente aos processos erosivos.

Nas classes de declividade que variam de 0 a $8 \%$ predominam os relevos plano e o suave ondulado, e ocupam $45 \%\left(3.162,3 \mathrm{Km}^{2}\right)$ e $25 \%$ $\left(1.768,3 \mathrm{Km}^{2}\right)$ da bacia, respectivamente. As menores declividades favorecem o processo de infiltração da água da chuva e a formação do solo, indicando terrenos estáveis com relação à erosão. Nas baixas declividades, a ação da gravidade é menor e, consequentemente, a intensidade do escoamento superficial e a do transporte de sedimentos são baixas, contendo os processos erosivos e com tendência de formação de elúvios. Essas declividades se apresentam por toda a área de estudo, predominando nas formas de relevo pediplano rochoso e planície costeira. As classes de declividade entre $8-20 \%\left(936 \mathrm{Km}^{2}\right)$ e $20-45 \%$ $\left(512 \mathrm{Km}^{2}\right)$, representadas por relevos ondulados a forte ondulados, também estão distribuídas por toda a bacia, porém, concentradas nas formas de relevo pediplano dissecado e tabuleiro costeiro, indicando estágio intermediário dos processos pedo-morfogenéticos, com tendência de formação de colúvios.

\section{Figura 2: Mapa de declividade da BHRSF}

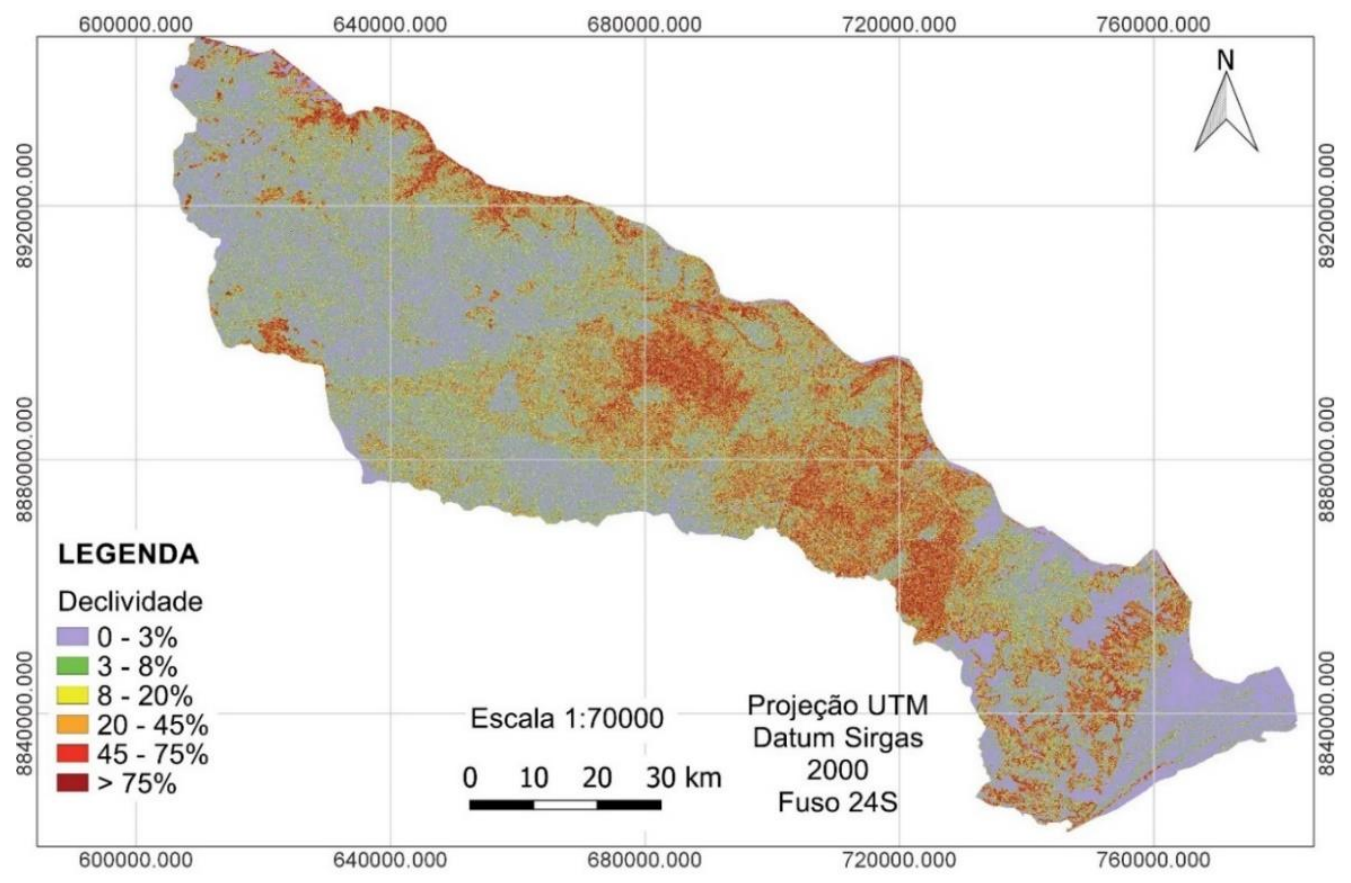

Fonte: Os autores (2020). 
Como não foi realizado o mapeamento do comprimento de rampa, as classes hipsométricas (Figura 3) foram relacionadas com as classes morfográficas da EMBRAPA (1999) e IPT (1981). De acordo com Bertoni e Lombardi Neto (2010), à medida que o comprimento da vertente aumenta, as águas da chuva ganham volume proporcionalmente, bem como a sua velocidade de escoamento, que aumentará progressivamente. Assim, a partir do mapa hipsométrico, foi possível inferir a influência do comprimento da vertente nos processos erosivos.

A área de estudo apresentou: 29\% (2039 $\mathrm{Km}^{2}$ ) de altitude até 100 metros, representada por relevo plano concentrado na planície costeira, tabuleiro costeiro e porções no entorno do rio São
Francisco do pediplano dissecado; 31\% (2205 $\mathrm{Km}^{2}$ ) entre 100 e 200 metros contornando as formas de relevo do tabuleiro costeiro e pediplano dissecado; e $36 \%\left(2606 \mathrm{Km}^{2}\right)$ com altitudes variando entre 200 e 300 metros, concentradas no pediplano rochoso. As altitudes superiores a 400 metros são inexpressivas na área de estudo, apresentando somente $0,2 \%\left(12 \mathrm{Km}^{2}\right)$ do total, sendo representadas pela Serra Negra, localizada no município de Poço Redondo, ponto mais alto de Sergipe. Dessa forma, nas áreas mais altas, a montante da bacia, os processos erosivos tendem a ser menos acentuados do que na jusante, região está propensa à formação de depósitos de sedimentos aluvionares e assoreamento dos corpos hídricos superficiais.

\section{Figura 3: Mapa hipsométrico da BHSRF}

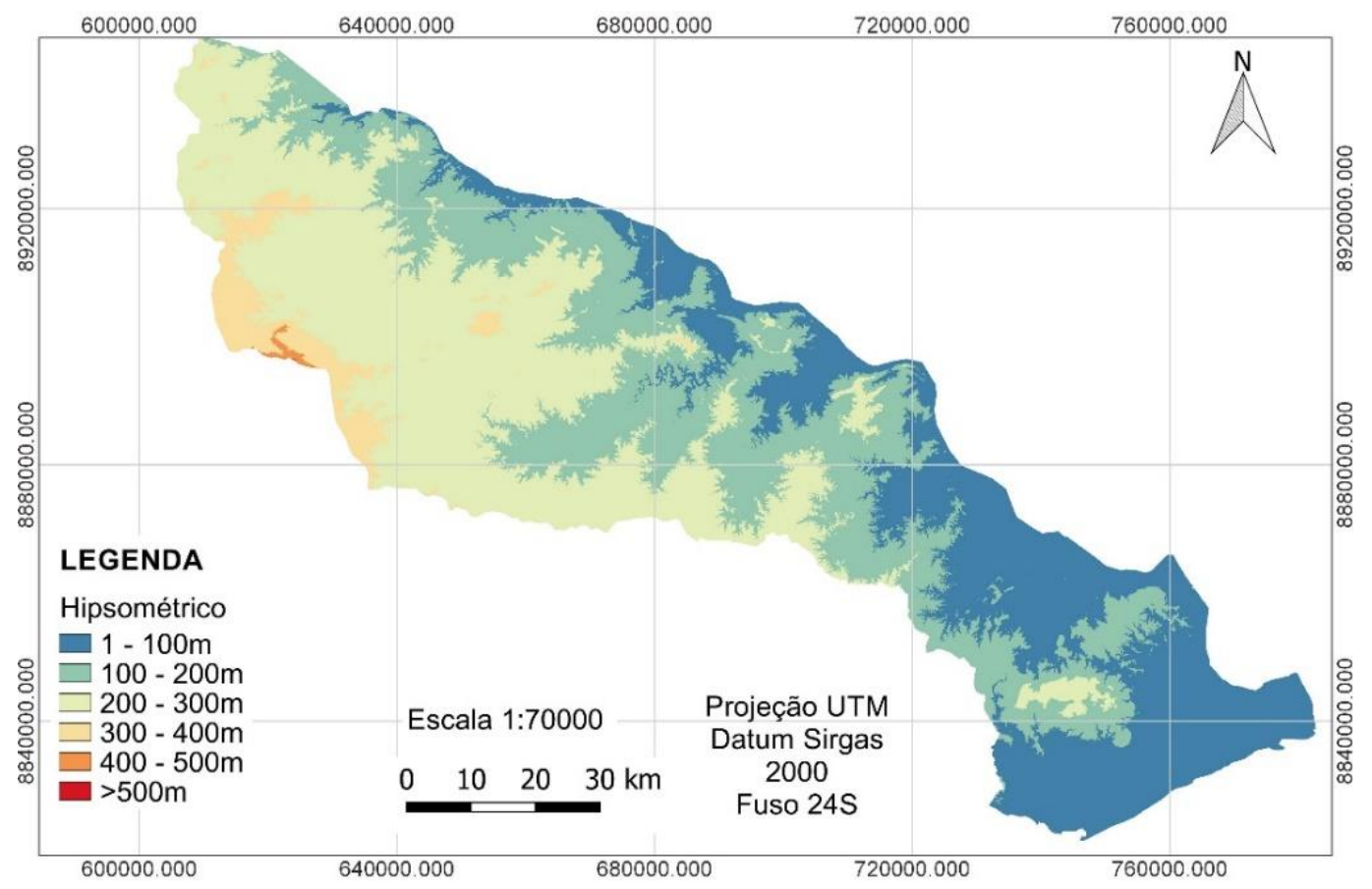

Fonte: Os autores (2020).

Como foi visto na metodologia, a erodibilidade da rocha/solo foi obtida por meio do Interpolador Kernel aplicada à densidade de drenagem da bacia (Figura 4). Adiferença dos graus de dissecação do relevo define a maior ou menor potencialidade da rocha/solo erodir (SANTOS; NASCIMENTO; BARROS, 2019). Dos dados extraídos do mapa, obtiveram-se as seguintes proporções: $54 \%\left(4.002,8 \mathrm{Km}^{2}\right)$ da área apresentam erodibilidade muito baixa, $17 \%$ $\left(1.215,1 \quad \mathrm{Km}^{2}\right)$ baixa, $13,5 \% \quad\left(990 \quad \mathrm{Km}^{2}\right)$ moderadamente baixa, $12,2 \% \quad\left(892,7 \quad \mathrm{Km}^{2}\right)$ moderadamente alta e 3,2\% $\left(238,5 \mathrm{Km}^{2}\right)$ alta. Já a classe de erodibilidade muito alta foi inexpressível.

De acordo com os mapas expostos, os pontos que apresentam baixa, moderadamente baixa, moderadamente alta e alta densidade de drenagem estão distribuídos na região centrooeste da bacia. Situam-se geologicamente no Domínio Macururé, pertencentes à Faixa de Dobramentos Sergipana. As rochas metassedimentares do Grupo Macureré, na área de estudo, são compostas, principalmente, por 
micaxistos, metassiltitos, metagrauvacas e metarritimitos (SANTOS et al., 1998). Sobre essas rochas predominam tipologias pedogênicas friáveis facilmente erodíveis, como os Neossolo
Litólico e Planossolo, em oposição ao Plintossolo, de maior resistência à erosão (EMBRAPA, 1999; BARROS et al. 2018).

\section{Figura 4: Mapa de erodibilidade da BHSRF}

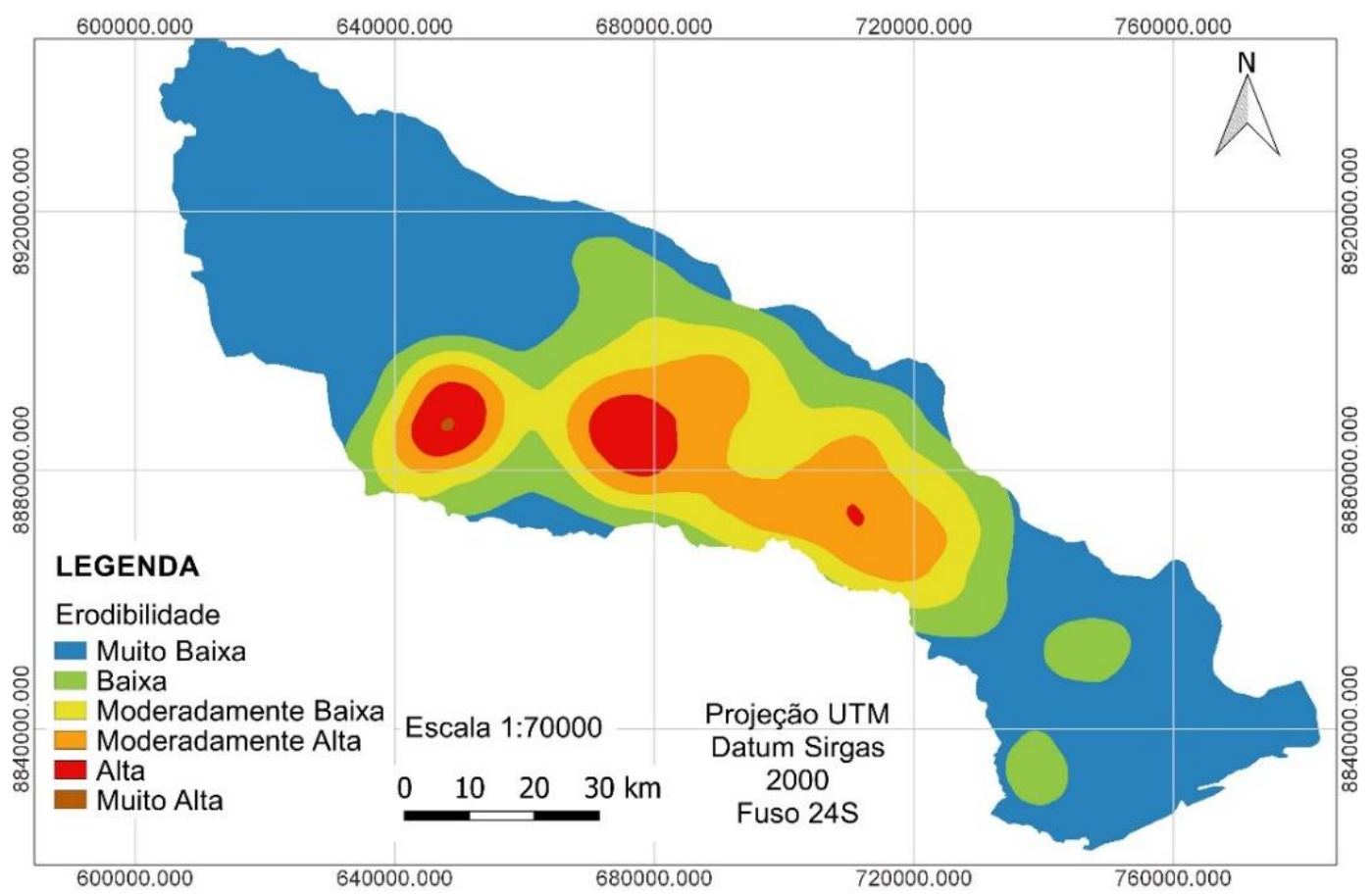

Fonte: Os autores (2020).

Segundo Santos e Nascimento (2019), as bacias hidrográficas que possuem alta densidade de drenagem são compostas por solos impermeáveis e com maior escoamento superficial. Essa afirmativa foi constatada na área de estudo, pois as regiões que apresentaram erodibilidade moderadamente alta e alta estão sobre os Neossolo Litólico e Planossolo, que possuem baixa permeabilidade. Esta característica, associada à pequena espessura dos solos predominantes na BHRSF são fatores agravantes, pois contribuem para um intenso escoamento superficial, favorecendo os processos erosivos.

Com os valores de precipitação média anual espacializados dentro do limite da bacia (Figura 5), foi possível perceber variabilidades significativas ao longo da sua extensão. A faixa litorânea é o local de maior precipitação, entre 1280 e $1400 \mathrm{~mm}$, correspondendo a $513 \mathrm{Km}^{2}$ $(7,1 \%)$ da extensão total, e a região semiárida, a de menor precipitação, entre $600 \mathrm{~mm}(26 \%)$ e $890 \mathrm{~mm}(27 \%)$. As áreas centrais são receptoras de grandes volumes de chuva, com taxas de precipitações intermediárias, variando de 890 a
$1280 \mathrm{~mm}$, o que correspondeu, proporcionalmente, às áreas de 1010, $9 \mathrm{Km}^{2}$ (14\%) e 1072, $1 \mathrm{Km}^{2}$ (15\%), respectivamente.

Bertoni e Lombardi Neto (2010) afirmam que o volume e a velocidade das enxurradas estão relacionados ao grau de declividade do terreno. Comparando o mapa de erosividade (Figura 5) com 0 da declividade (Figura 2), nota-se que a região central, além de apresentar grandes declives, recebe grandes volumes de chuva. Assim, pode-se inferir que, nessas condições, a velocidade de escoamento da água da chuva é grande, ocasionando menores taxas de infiltração e maior intensidade erosiva. $O$ escoamento superficial irá percorrer pelas encostas até chegar à planície costeira, onde perderá sua força devido às baixas declividades. Esta mesma região é responsável por receber a maior quantidade de água precipitada na bacia. Logo, esses dois fenômenos associados condicionam as áreas costeiras a eventos de alagamentos, enchentes e inundações. Diante do exposto, pode-se constatar que a erosividade da chuva poderá ser um agente bastante favorecedor à erosão tanto na região central, quanto na planície costeira da bacia. 
Figura 5: Mapa de erosividade da chuva da BHRSF

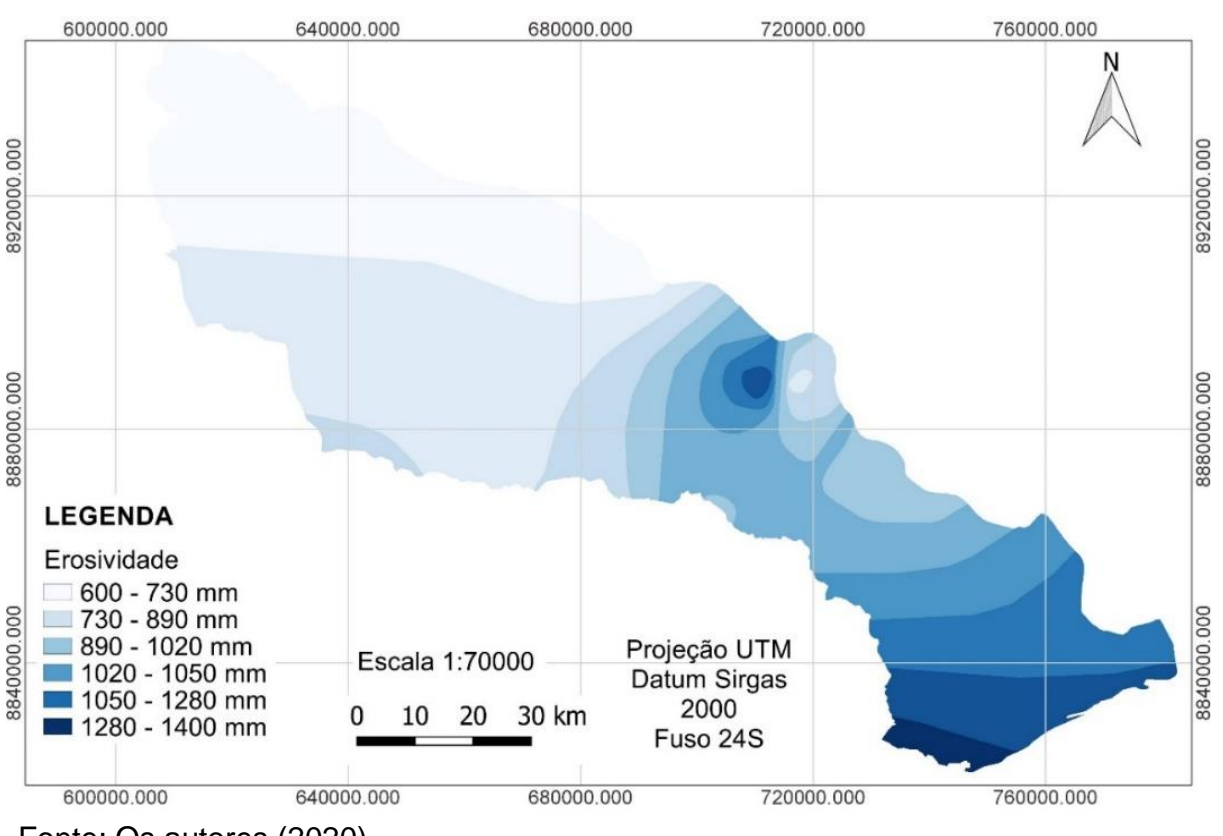

Fonte: Os autores (2020).

Analisando a Figura 6, percebe-se que houve uma grande supressão da cobertura vegetal para se converter em áreas de pastagens e cultivo agrícola.

A pastagem é uma característica da área de estudo, devido à criação de gado de leite, sendo a região conhecida como Bacia Leiteira de
Sergipe. Por outro lado, os cultivos agrícolas são característicos dos perímetros irrigados de Propriá, Cotingiba e Betume, que representam $10 \%\left(685 \mathrm{Km}^{2}\right)$ da bacia. Estes perímetros surgiram em locais onde a mata ciliar foi carreada pela erosão nos taludes do rio São Francisco (HOLANDA et. al. 2009).

\section{Figura 6: Mapa de cobertura do solo da BHRSF}

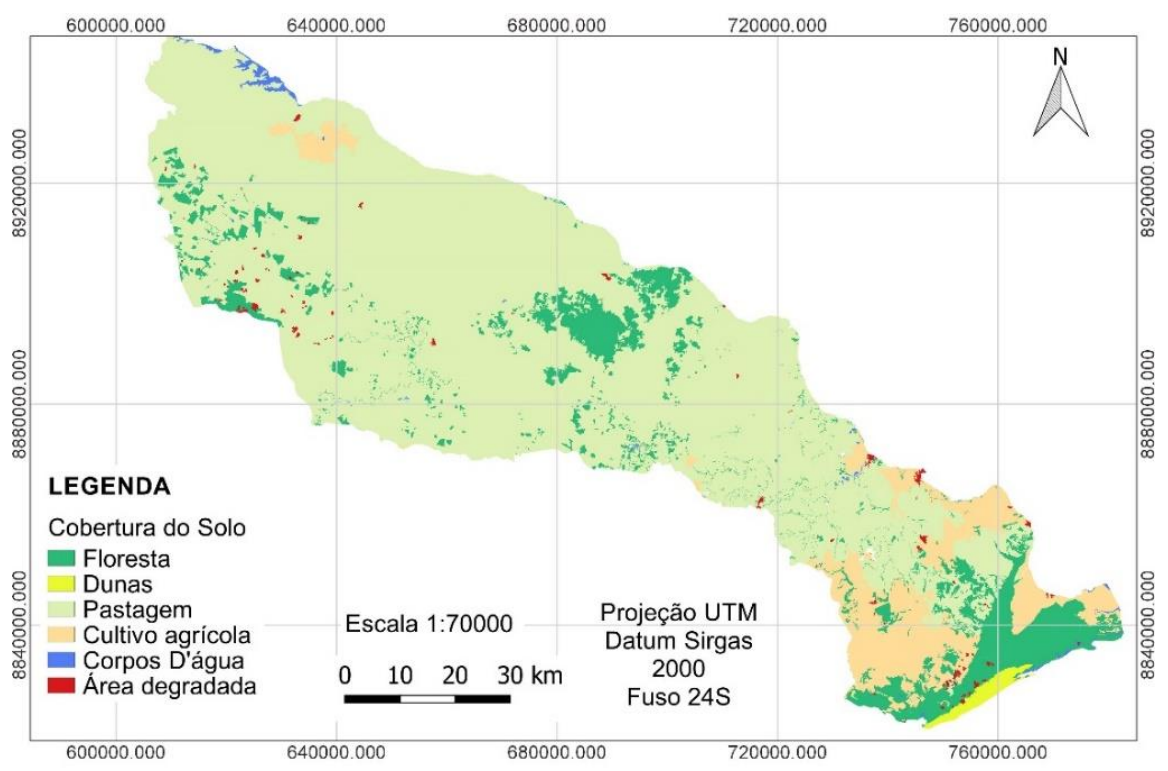

Fonte: Modificado da Semarh (2013). 
As dunas se apresentam numa pequena faixa litorânea, sendo representada por, aproximadamente, 0,6\% $\left(45 \mathrm{Km}^{2}\right)$ do território da bacia, enquanto os corpos d'água correspondem a 0,5\% (38 $\left.\mathrm{Km}^{2}\right)$ e as áreas degradadas 0,4\% (31 $\left.\mathrm{Km}^{2}\right)$.

As áreas de florestas $\left(865,6 \mathrm{Km}^{2}\right)$ são muito inferiores às áreas de pastagens $\left(5501,7 \mathrm{Km}^{2}\right)$, correspondendo, respectivamente, as proporções de $12 \%$ e $77 \%$ da extensão total, se mostrando uma bacia com alto potencial de degradação ambiental. Visto que é a principal responsável pelo abastecimento de água do Estado, é necessário que a mesma seja monitorada e que as pastagens, principalmente próximas aos corpos hídricos e em áreas com maior declive, sejam recuperadas e conservadas.

Além disso, a pouca vegetação encontrada na bacia intensifica os processos erosivos, demandando manejo adequado para reduzir o escoamento superficial e o carreamento de sedimentos para os corpos hídricos, sem que comprometa a qualidade das águas.

Como descrito na metodologia, o mapa de suscetibilidade à erosão da Bacia Hidrográfica do Rio São Francisco foi obtido através da integração dos mapas de declividade, hipsometria, erodibilidade e Erosividade (Figura 7 e Tabela 8).

Figura 7: Mapa de suscetibilidade à erosão da BHRSF

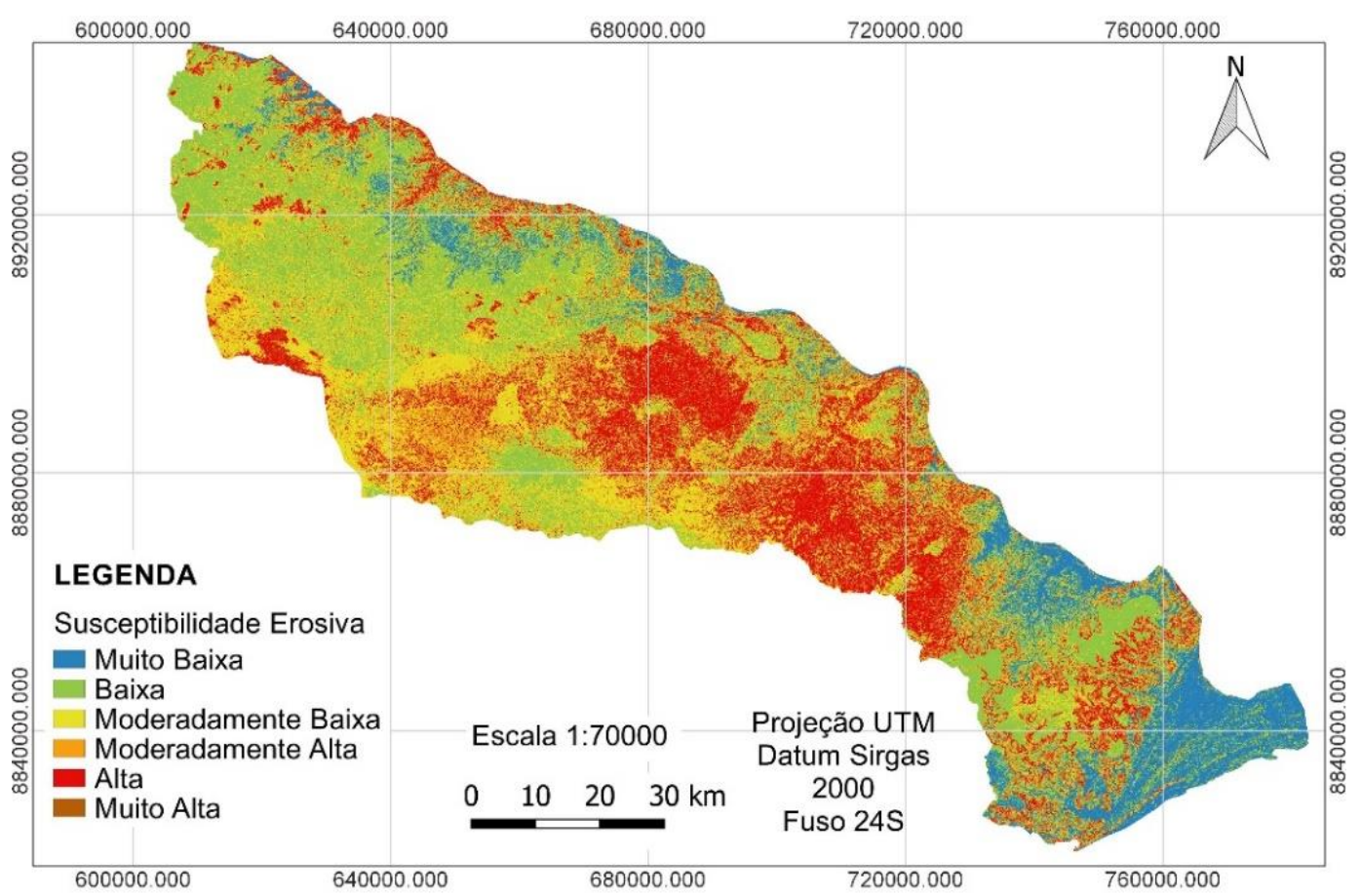

Fonte: Os autores (2020).

Tabela 1: Suscetibilidade à erosão por classe (em \% e Km²)

\begin{tabular}{ccc}
\hline Suscetibilidade & Área (\%) & Área $\left.\mathbf{( K m}^{2}\right)$ \\
\hline Muito Baixa & 11,4 & 815,6 \\
\hline Baixa & 28,2 & 2013,6 \\
\hline Moderadamente Baixa & 25,7 & 1836,4 \\
\hline Moderadamente Alta & 14,6 & 1043,9 \\
\hline Alta & 20,1 & 1438,3 \\
\hline Muito Alta & 0,1 & 7,4 \\
\hline
\end{tabular}

Fonte: Os autores (2020). 
Para a Bacia Hidrográfica do rio São Francisco, foi identificado o predomínio das classes muito baixa, baixa e moderadamente baixa de suscetibilidade à erosão, que somadas totalizam $65 \%$ da área total. Estas classes são evidenciadas em locais de baixos declives, hipsometria elevada, erodibilidade muito baixa e precipitação entre 600 e $890 \mathrm{~mm}$.

Respostas semelhantes a estas também foram obtidas por Santos (2019) na análise da fragilidade ambiental da Bacia Hidrográfica do Rio Japaratuba - SE, utilizando a mesma metodologia aqui adotada. Nesse trabalho, a autora encontrou o percentual de $78,78 \%$ da área de estudo com classes muito baixa $e$ moderadamente baixa de fragilidade ambiental potencial, aqui denominada suscetibilidade erosiva. Essas classes se concentraram em regiões de baixa declividade, baixa erodibilidade e alta precipitação, se tornando, assim, áreas propícias ao assoreamento de sedimentos gerados nas áreas de maior fragilidade ambiental.

No estudo elaborado por São Miguel, Medeiros e Gomes (2018) na bacia do ribeirão São Pedro - MS, foram considerados, para a elaboração do mapa de fragilidade ambiental, os dados referentes à declividade, solos, áreas prioritárias, clima, uso da terra e cobertura vegetal da bacia. Assim, foi encontrada também a predominância da classe baixa de fragilidade, cerca de $60,44 \%$ do total da área da bacia.

Portanto, mesmo que a BHRSF tenha predominância de áreas com baixa suscetibilidade à erosão, estes resultados não podem ser negligenciados, mas, sim, tratados como relevante subsídio ao gerenciamento e monitoramento da área. Considerando os aspectos como a extensão, presença de relevos ondulados e de solos impermeáveis e os maiores índices de pluviosidade a montante da bacia, estes podem causar sérios danos socioambientais.

As classes moderadamente alta e alta somadas correspondem a $34 \%$ do total e aparecem na região central da bacia, sendo encontradas em áreas com declive e hipsometria elevadas, solos pedregosos e consideráveis volumes de chuva, potencializando os efeitos do escoamento superficial e, consequentemente, os altos índices de suscetibilidade à erosão. Tal situação foi comprovada no trabalho de Fontes (2016), ao monitorar os usos de estacas no controle dos processos erosivos em taludes do baixo curso do rio São Francisco, quando se observaram maiores índices de erosão. Estes foram justificados pelo aumento do escoamento superficial decorrente dos meses de maior precipitação chuvosa e da textura arenosa dos solos dos taludes.

Assim, os resultados apresentados corroboram com as variáveis utilizadas e na definição da hierarquia adotada para analisar a suscetibilidade à erosão na BHRSF através das técnicas de geoprocessamento.

O mapa de vulnerabilidade à erosão foi resultado da integração do mapa de suscetibilidade erosiva com o de cobertura do solo (Figura 8). A Tabela 9 apresenta os valores proporcionais a cada classe do mapa de vulnerabilidade.

Com os valores da área de cada classe obtidos do mapa de suscetibilidade e vulnerabilidade, foi construído um gráfico, apresentado na Figura 9, para efetuar a análise comparativa entre a proporção de cada classe e auxiliar na compreensão do potencial erosivo da bacia BHRSF.

A partir da análise gráfica, percebe-se que houve um aumento expressivo das áreas que apresentaram suscetibilidade erosiva moderadamente baixa, moderadamente alta e alta. No entanto, as áreas com vulnerabilidade erosiva muito baixa e baixa foram maiores do que as áreas suscetíveis à erosão. Isso ocorreu em função da predominância da pastagem.

Os sistemas de pastagens que levam em consideração a capacidade de suporte do solo e boas práticas de manejo, como o sistema de rotação de pastos, o controle da taxa de lotação de animais e de queimadas (WADT et al., 2003), são coberturas vegetais apropriadas ao controle da erosão. Ross (2011) também estabeleceu que as pastagens cultivadas sem a presença de rebanho, oferecem alta proteção para o solo frente aos processos erosivos. A predominância de áreas com baixa vulnerabilidade erosiva decorrente da maior cobertura dos solos por pastagens também foi constatada por Moura et. al. (2017), no estudo da estimativa da perda de solo para a mesma área de estudo, validando assim os resultados aqui obtidos.

Apesar de a área apresentar baixa vulnerabilidade erosiva em função das pastagens, em um cenário futuro, a conversão das pastagens em cana-de-açúcar e o uso da mecanização na produção de grãos desencadeiam a 
desestruturação do solo e intensificação do processo erosivo. Outro aspecto a considerar é a transformação gradativa dos perímetros irrigados, inicialmente direcionados aos pequenos produtores, em grandes empresas privadas que ocupam grande área para práticas agrícolas. Tradicionalmente, a rizicultura predominava nas áreas das várzeas alagadas naturalmente pelas enchentes e enriquecidas pelo húmus contido nos sedimentos carreados pelo rio São Francisco. No entanto, com a implantação das barragens no rio, principalmente a Hidrelétrica de Xingó, ocorreu expansão das fronteiras de rizicultura e a necessidade de irrigação. Nesse contexto, as baixas áreas de vulnerabilidade erosiva tendem a aumentar com a propensão do aumento da agroindústria no Baixo São Francisco, como destacado por Silva (2018).

Figura 8: Mapa de vulnerabilidade à erosão da BHRSF

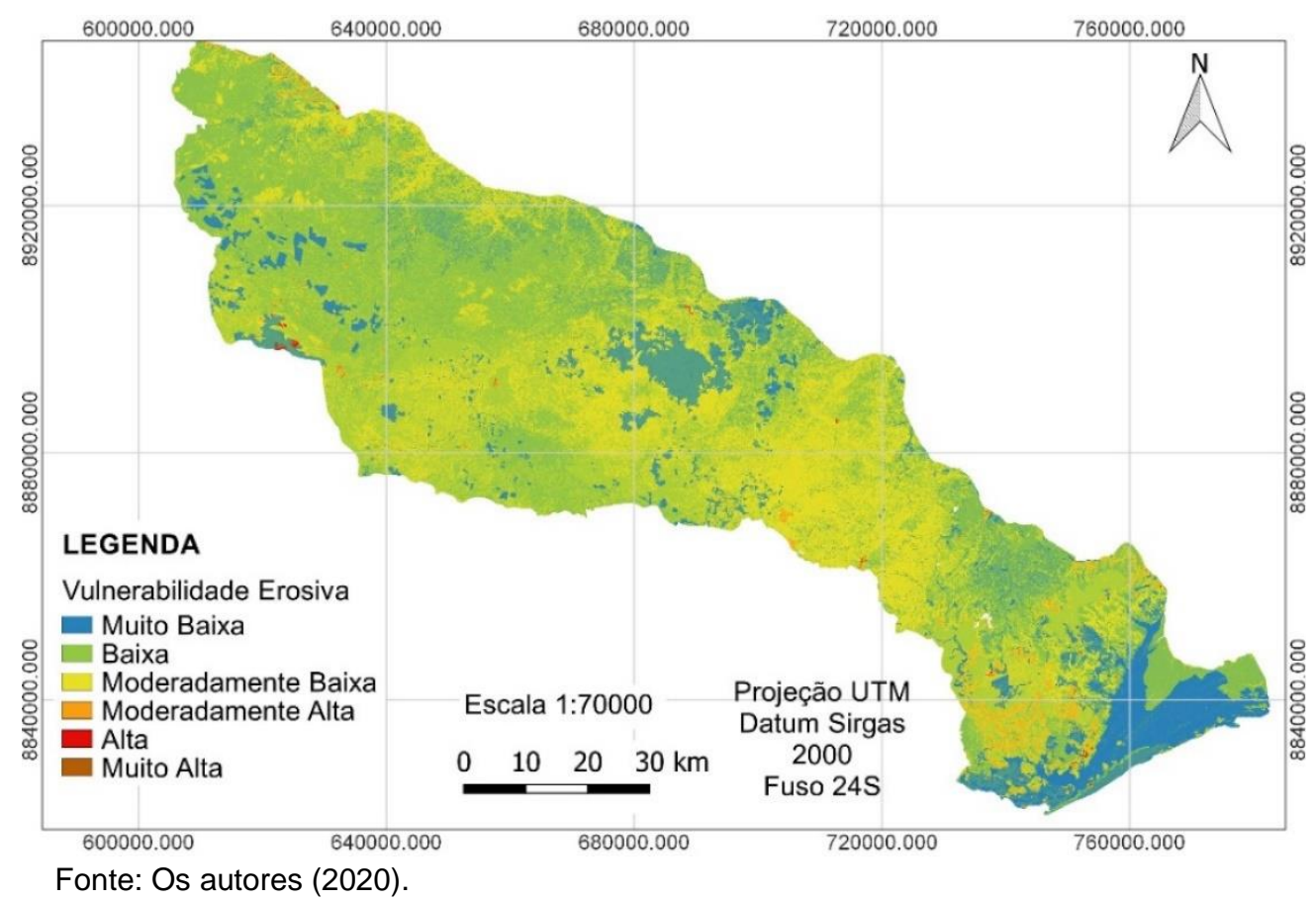

Tabela 2: Vulnerabilidade à erosão por classe

\begin{tabular}{ccc}
\hline Vulnerabilidade & Área (\%) & Área $\left.\mathbf{( K m}^{2}\right)$ \\
\hline Muito Baixa & 19,8 & 1410,6 \\
\hline Baixa & 60,8 & 4329,0 \\
\hline Moderadamente Baixa & 19,2 & 1362,9 \\
\hline Moderadamente Alta & 0,1 & 4,9 \\
\hline Alta & 0,1 & 8,4 \\
\hline Muito Alta & 0 & 0,3 \\
\hline
\end{tabular}

Fonte: Os autores (2020).

Desta forma, é necessária a adoção de técnicas naturais conservacionistas que levem em consideração as limitações do local, visto que houve uma perda drástica de vegetação nativa, o que coloca em risco a estabilidade das variáveis ambientais. Dentre as técnicas que podem ser aplicadas para a conservação do solo e para a minimização da ação dos agentes erosivos, podem ser citados: o terraceamento de encostas, a rotação de culturas, o recobrimento do solo com matéria orgânica morta e, principalmente, a recomposição da vegetação ciliar e o reflorestamento.

A rotação de culturas em áreas produtivas, a recomposição da vegetação ciliar e o reflorestamento são técnicas de proteção, 
minimização e recuperação de caráter vegetativo. É importante ressaltar que, no processo de reflorestamento, é necessária a preparação do solo em nível com sulcos e camalhões, visando minimizar a perda de solo e nutrientes por escoamento superficial, plantio por coveamento em nível com espaçamento previamente determinado e combinação de espécies de diferentes grupos ecológicos de pioneiras, secundárias e climáxicas. Concomitantemente, aplicam-se as técnicas edáficas, destacando a adubação orgânica com recobrimento do solo com serapilheira e calagem, para correção da acidez do solo pela aplicação do cálcio, que aumenta o aproveitamento do fósforo pelas plantas e a fixação de nitrogênio pelos organismos. Por fim, o terraceamento das encostas completa a proteção da superfície, reduzindo a velocidade de escoamento, proporcionando a maior infiltração e o armazenamento das águas das chuvas, as quais podem ser reaproveitadas ou não para outras atividades.

\section{Figura 9: Áreas por classe de suscetibilidade e vulnerabilidade à erosão}

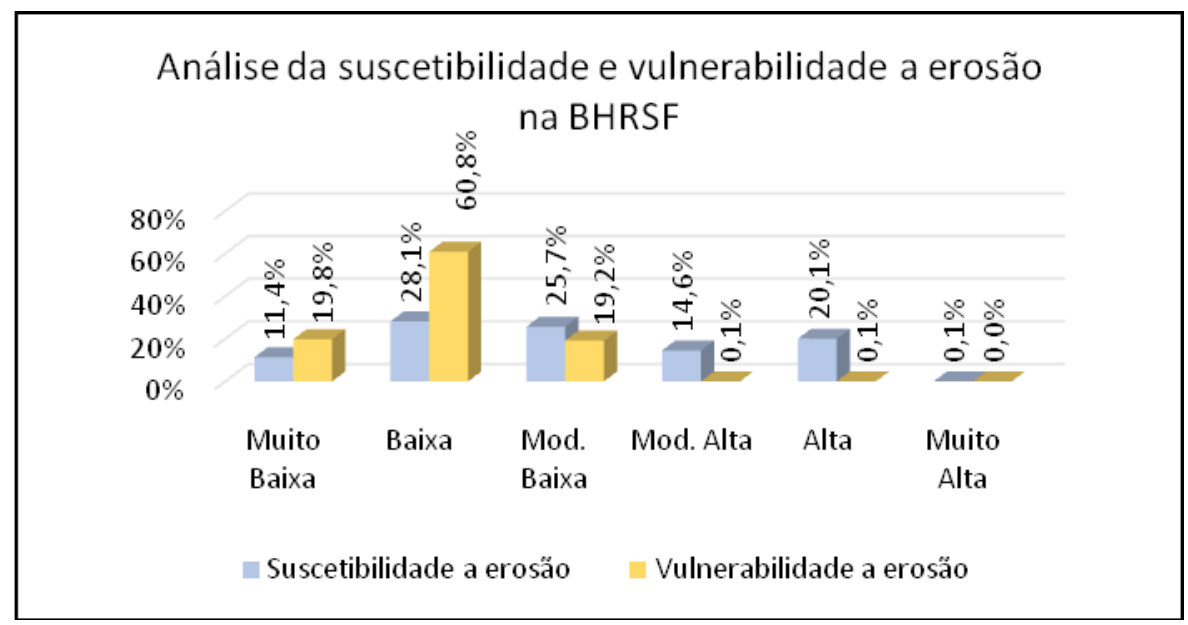

Fonte: Os autores (2020).

\section{CONCLUSÃO}

As técnicas de geoprocessamento aplicadas foram eficazes na delimitação das áreas suscetíveis e vulneráveis aos processos erosivos da Bacia Hidrográfica do Rio São Francisco (BHRSF), no estado de Sergipe. Dessa forma, o objetivo deste trabalho foi atingido e destaca-se a álgebra de mapas por análise hierarquizada dos fatores naturais (erodilidade, erosividade e topografia) e antrópicos (cobertura do solo). $\mathrm{O}$ método AHP mostrou-se um instrumento adequado em análises ambientais, possibilitando inferir como cada fator natural e antrópico interferem nos processos erosivos da área de estudo. O uso das técnicas AHP e da álgebra de mapas se mostraram eficazes, uma vez que o AHP minimiza a ocorrência de erros na determinação dos pesos para as variáveis utilizadas, e a álgebra de mapa realizada em todo o processo de integração facilitou a elaboração dos produtos intermediários e final. É importante ressaltar que a plataforma unificada de dados temáticos proporcionada pelo Banco de Dados Georreferenciados permite 0 armazenamento, consultas, atualizações, dentre outras funções inerentes às geotecnologias.

Diante dos resultados obtidos, verificou-se que a BHRSF apresenta, predominantemente, baixo potencial à suscetibilidade erosiva, evidenciada através da análise integrada dos agentes naturais. Estes resultados são necessários para subsidiar ações de caráter preventivo, visto a importância socioeconômica e ambiental da bacia. Com relação à vulnerabilidade aos processos erosivos, pôde-se constatar a predominância de regiões com baixo potencial erosivo, em função das áreas de pastagens que se estendem por toda bacia. Por mais que este uso tenha se mostrado como um artifício conservacionista, é fundamental adotar medidas de gestão e planejamento, pois, devido à intensificação da prática, podem-se causar 
impactos que venham a comprometer o equilíbrio ambiental a médio e longo prazo.

A análise das áreas suscetíveis e vulneráveis aos processos erosivos na BHRSF é uma contribuição para estudos futuros e uma ferramenta de auxílio na tomada de ações necessárias, pelos órgãos competentes, à minimização dos impactos ambientais. Dessa forma, sugerem-se a implantação de técnicas que estabilizem os solos das vertentes $e$ a recuperação da vegetação, como preconiza a Lei Federal $n^{\circ}$ 12.651/2012, que dispõe sobre a proteção da vegetação nativa (BRASIL, 2012). Nesse sentido, têm-se o disciplinamento das águas superficiais e subsuperficiais e a contenção das encostas, medidas consagradas na literatura científica para evitar, minimizar, recuperar, gerenciar e monitorar os processos erosivos em áreas urbanas e/ou rurais. Recomenda-se a recuperação dos biomas Mata Atlântica e Caatinga, os quais foram convertidos, principalmente, em pastagens e cana-de-açúcar.

A importância da recuperação desses dois biomas reside na conservação e restabelecimento da biodiversidade em decorrência da sua relevância estratégica para os ecossistemas semiárido, agreste e litorâneo. Dessa forma, sugere a criação de Unidades de Conservação a partir da recomposição da mata ciliar do rio São Francisco e de seus afluentes, de acordo com a legislação vigente, levando em consideração as comunidades ribeirinhas e sua relação com o rio. Propõe-se a adoção de um modelo de exploração e de reconstituição da mata ciliar com sustentabilidade socioeconômica e ambiental, a partir de espécies nativas que possam ser exploradas pela população sem a supressão da vegetação natural. Para a recuperação dos biomas supracitados, é recomendável que se priorizem as áreas com solos expostos, que favorecem a erosão, a sensibilização das comunidades tradicionais por meio da educação ambiental, bem como políticas públicas que atendam ao agronegócio, de pequeno a grande porte, à luz da sustentabilidade ambiental e do crescimento socioeconômico.

Com relação aos pequenos e médios produtores, destaca-se a adoção de políticas públicas que incentive a agricultura multifuncional, para que esses agricultores internalizem os custos e evitem conflitos socioambientais. Exemplos de propostas de políticas públicas de incentivo aos pequenos e médios agricultores são a isenção de impostos, o pagamento de subsídios ou abertura de canais de distribuição de produtos orgânicos, neste caso, mediante a compra, por parte do Estado, de produtos destinados à merenda de creches, escolas, abrigos e asilos públicos.

A sistemática adotada neste trabalho foi promissora, gerando produtos cartográficos finais capazes de traduzir a realidade ambiental de maneira simples e de fácil compreensão, os quais podem ser considerados documentos técnicogerenciais de subsídio de manejo, uso e ocupação do solo e dos recursos hídricos superficiais. Dessa forma, a contribuição fundamental é a prevenção de processos de degradação das bacias, direcionando os locais potenciais de intensificação dos processos erosivos e, consequentemente do assoreamento e contaminação dos recursos hídricos.

\section{REFERÊNCIAS}

ALBUQUERQUE, J. Erosividade das chuvas na bacia hidrográfica do rio Apeú, região nordeste do estado do Pará. 2013. 70f. Tese (Doutorado em Agronomia) - Faculdade de Ciências Agronômicas, Universidade Estadual Paulista, São Paulo, São Paulo, 2013.

ALMEIDA FILHO, G. S. Em Foco: controle de erosão. Revista Fundações e Obras Geotécnicas, São Paulo, v. 5 , n. 54 , p. $72-83$, mar. 2015.

BARROS, E. N. S; VIOLA, M. R.; RODRIGUES, M.; ASSAID, J.; MELLO, C. R.; AVANZI, J. C.; GIONGO, M. Modelagem da erosão hídrica nas bacias hidrográficas dos rios Lontra e Manoel Alves Pequeno, Tocantins. Revista Brasileira de Ciências Agrárias, v. 13, n. 1, p. 1-9, abr. 2018.

BERNARDI, E. C. S.; PANZIERA, A. G.; SWAROWSKY, A.; BURIOL, G. A. Bacia hidrográfica como unidade de gestão ambiental. Disciplinarum Scientia, Santa Maria, v. 13, n. 2, p. 159-168, dez. 2012.

BERTONI, J.; LOMBARDI NETO, F. Conservação do solo. 7. ed. São Paulo: Ícone, 2010.

BRADY, N. C. Erosão do solo e seu controle. In: FIGUEIREDO FILHO, A. B. N. (Org.). Natureza e propriedades dos solos. 7. ed. Rio de Janeiro: Freitas Bastos, 1989.

BRASIL. Lei no 12.651, de 25 de maio de 2012.

Dispõe sobre a proteção da vegetação nativa; altera as Leis nos 6.938, de 31 de agosto de 1981, 9.393, de 19 de dezembro de 1996, e 11.428, de 22 de dezembro de 
2006; revoga as Leis nํs 4.771, de 15 de setembro de 1965, e 7.754, de 14 de abril de 1989, e a Medida Provisória ํㅡ 2.166-67, de 24 de agosto de 2001; e dá outras providências. Brasília, 2012. Disponível em: http: //www.planalto.gov.br/ccivil_03/_Ato2011-

014/2012/Lei/L12651.htm. Acesso em: 11 ago. 2019.

CÂMARA, G. Modelos, linguagens e arquiteturas para Bancos de Dados Geográficos. 1995, $238 f$. Tese (Doutorado em Computação Aplicada) - Instituto Nacional de Pesquisas Espaciais, São José dos Campos. 1995.

CARVALHO, M. E. S.; FONTES A. L. Estudo ambiental da Zona Costeira Sergipana como subsídio ao ordenamento territorial. Geonordeste, v. 25, n. 2, p. 115, 2006.

COELHO, A. L. N. Sistema de Informações Geográficas (SIG) como suporte na elaboração de planos diretores municipais. Caminhos de Geografia, v. 10, p. 93-110, jun. 2009.

CORRECHEL, V. Avaliação de índices de erodibilidade do solo através da técnica da análise da redistribuição do "Fallout" do ${ }^{137}$ Cs. 2003. $99 \mathrm{f}$. Tese (Doutorado em Ciências) - Centro de Energia Nuclear na Agricultura, Universidade de São Paulo, Piracicaba, 2003.

CREPANI, E.; MEDEIROS, J. S.; HERNANDEZ FILHO, P.; FLORENZANO, T. G.; DUARTE, V.; BARBOSA, C. C. F. Sensoriamento remoto e geoprocessamento aplicados ao zoneamento ecológico-econômico e ao ordenamento territorial. São José dos Campos: INPE, 2001. 103p.

CUIABANO, M. N.; NEVES, S. M. A. S.; NUNES, M. C. M.; SERAFIM, M. E.; NEVES, R. J. Vulnerabilidade ambiental à erosão hídrica na Sub-bacia do córrego do Guanabara/Reserva do Cabaçal-MT Brasil. Geociências, v. 36, n. 1, p. 138-153, 2017.

DIAS, V. S. B.; SILVA, A. BARROS. AHP na modelagem da vulnerabilidade ambiental do Mini Corredor Ecológico Serra das Onças (BA). Revista Brasileira de Cartografia, v. 66, n. 6, p. 1363-1377, 2014.

EMBRAPA. Empresa Brasileira de Pesquisas Agropecuária. Centro Nacional de Pesquisa de Solos. Sistema brasileiro de classificação de solos. 2 ed. Rio de Janeiro: Embrapa Solos, 1999.

FAO. Food and Agriculture Organization of the United Nations and Intergovernmental Technical Panel on Soils. Status of the World's Soil Resources (SWSR). Rome: FAO, 2015, 60p.
FITZ, P. R. Geoprocessamento sem complicação. 1. ed. São Paulo: Oficina de Textos, 2008. 160p.

FONTES, C. D. S. Dinâmica dos processos erosivos em taludes do baixo curso do Rio São Francisco: desafios para seu controle com uso de geotêxteis. 2016. 184 f. Tese (Pós-Graduação em Geografia) Universidade Federal de Sergipe, São Cristóvão, 2016.

IPT. Instituto de Pesquisas Tecnológicas. Mapeamento Geomorfológico do Estado de São Paulo. São Paulo: IPT, 1981. 94p.

GDOURA, K.; ANANE, M.; JELLALI, S. Geospatial and multi-criteria analysis to rank suitable sites of shallow aquifer recharge with reclaimed water: application to Nabeul - Hammamet groundwater. Resources, Conservations and Recyclin, v. 104, p. 19-30, abr. 2014.

GOBBI, E.; BERTOL, I.; BARBOSA, F. T.; WERNER, R. S.; RAMOS, R. R.; PAZ-FERREIRO, J.; GLEBER, L. Erosão hídrica associada a algumas variáveis hidrológicas em pomar de maçã submetido a diferentes manejos do solo. Revista Brasileira de Ciência do Solo, v. 35, n. 3, p. 1013-1024, out. 2011.

GUERRA, A. J. T.; CUNHA, S. B. Geomorfologia e meio ambiente. 3. ed. Rio de Janeiro: Bertand Brasil, 2000. 372p.

HERNANI, L. C.; KURIHARA, C. H.; SILVA, W. M. Sistemas de manejo de solo e perdas de nutrientes e matéria orgânica por erosão. Revista Brasileira de Ciências do Solo, Mato Grosso do Sul, v. 23, n. 1, p. 145-154, abr. 1999.

HOLANDA, F. S. R.; BANDEIRA, A. A.; ROCHA, I.P.; ARAÚJO FILHO, R. N.; RIBEIRO, L. F.; ENNES, M. A. Controle da erosão em margens de cursos d'água: das soluções empíricas à técnica da bioengenharia de solos. Raega, n. 17, p. 93-101, 2009.

INPE. Instituto Nacional de Pesquisas Espaciais. Banco de Dados Geomorfométricos do Brasil. Projeto Topodata. São José dos Campos, 2011. Disponível em:

http://www.webmapit.com.br/inpe/topodata/. Acesso em: 23 mar. 2020.

LONGLEY, P. A.; GOODOCHILD, M.F.; MAGUIRE, D. J.; RHIND, D. W. Sistemas e ciências da informação geográfica. Porto Alegre: Bookman, 2013. 540p.

NAGHETTI, M. N.; PINTO, E. J. A. Hidrologia estatística. Belo Horizonte: CPRM, 2007. 552p.

MAGALHÃES, R. A. Erosão: definições, tipos e formas de controle. In: SIMPÓSIO NACIONAL DE CONTROLE 
DE EROSÃO, 7., 2001, Goiânia. Anais... Goiânia: ABGE, 2001, p. 11-22.

MEDEIROS, P. R. P.; KNOPPERS, B. A.; SANTOS JUNIOR, R. C.; SOUZA, W. F. L. Aporte fluvial e dispersão de matéria particulada em suspensão na zona costeira do rio São Francisco (SE/AL).

Geochimica Brasiliensis, v. 21, n. 2, p. 212-231, 2007.

MIRANDA, J. I. Fundamentos de sistemas de informações geográficas. Brasília: Embrapa, 2005. 425p.

MOURA, M. M.; FONTES, C. S.; SANTOS, M. H.; ARAUJO FILHO, R. N.; HOLANDA, F. S. R. Estimativa de perda de solo no Baixo São Francisco Sergipano. Scientia Agraria, Curitiba, v. 18, n. 2, p. 126-135, 2017.

NASCIMENTO, P. S. R. Subsídio à gestão ambiental hidroviária: o empreendimento hídrico Santa Maria da Serra. 2004. 189f. Tese (Doutorado em Geociências) Instituto de Geociências e Ciências Exatas,

Universidade Estadual Paulista, Rio Claro, 2004.

; GARCIA, J. G. Atualização do mapa de vegetação natural e do uso da terra na Sub-bacia do Baixo Piracicaba (SP) com o auxílio de imagens TM/Landsat-5. Estudos Geográficos, v. 2, n. 2, p. 3145, dez. 2004.

; PETTA, R. A. Análise das similaridades das cartas de vulnerabilidade à erosão realizada por dois operadores de álgebras de mapas. Revista da Escola de Minas, v. 61, p.135-140, 2008.

PEREIRA, E. A.; SOUSA; A. P.; CAMPOS, S. Mapeamento do uso do solo nas sub-bacias dos córregos São José e Água do Ventura. Revista Irriga, Bauru, v. 7, n. 3 p. 191-200, out. 2002.

PEREIRA, S. B.; PRUSKI, F. F.; SILVA, D. D.; MATOS, A. T. Desprendimento e arraste do solo pelo escoamento superficial. Revista Brasileira de Engenharia Agrícola e Ambiental, v.7, n. 3, p.423429, out. 2003.

PIMENTA, L. B.; BELTRÃO, N. E. S.; DA SILVA GEMAQUE, A. M.; TAVARES, P. A. Processo Analítico Hierárquico (AHP) em ambiente SIG: temáticas e aplicações voltadas à tomada de decisão utilizando critérios espaciais. Interações, v. 20, n. 2, p. 407-420, jun. 2019.

PINESE JÚNIOR, J. F.; RODRIGUES, S. C. O método de análise hierárquica - AHP - como auxílio na determinação da vulnerabilidade ambiental da Bacia Hidrográfica do Rio Piedade (MG). Revista do Departamento de Geografia, v. 23, p. 4-26, 2012.
REZENDE, P. S.; MARQUES, D. V.; OLIVEIRA, L. A. Construção de modelo e utilização do método de Processo Analítico Hierárquico- AHP para mapeamento de risco à inundação em área urbana. Revista Caminhos da Geografia, v. 18, n. 61, p. 1-18, mar. 2017.

RIBEIRO, T. C. S. C. Probabilidade e estatística. Londrina: Educacional, 2015, 232p.

RIBEIRO, A. S.; MINCATO, R. L.; CURI, N.; KAWAKUBO, F. S. Vulnerabilidade ambiental à erosão hídrica em uma sub-bacia hidrográfica pelo processo analítico hierárquico. Revista Brasileira de Geografia Física, v. 9, n. 1, p. 16-31, 2016.

ROCHA, I. P. Relação entre a erosão marginal, atributos físicos do solo e variáveis hidrológicas e climáticas no baixo São Francisco sergipano. 2009. 74f. Dissertação (Mestrado em Agroecossistemas) Núcleo de Pós-Graduação e Estudos em Recursos Naturais, Universidade Federal de Sergipe. São Cristóvão, 2009.

ROSS, J. L. S. Análise empírica da fragilidade dos ambientes naturais e antropizados. Revista do Departamento de Geografia, São Paulo, v. 8, p.63-74, mar. 1994.

Geografia do Brasil. 6. ed. São Paulo: Editora da USP, 2011. 552p.

SAATY, T. L. Decision making with the analytic hierarchy process. International Journal of Services Sciences, v. 1, n. 1, p. 83-98, jan. 2008.

How to make a decision: the Analytic Hierachy Process. Interfaces, v. 24, n. 6, p. 19-43, set. 1994.

SALOMÃO, F. X. T. Controle e prevenção dos processos erosivos. In: GUERRA, A. J. T.; SILVA, A. S.; BOTELHO, R. G. M. Erosão e conservação dos solos: conceitos, temas e aplicações. Rio de Janeiro: Bertrand Brasil, 1999. p. 229-265.

\footnotetext{
SANTOS, L. A. N. Geoprocessamento aplicado na análise da fragilidade ambiental da bacia hidrográfica do rio Japaratuba - SE. 2019. $45 f$. Trabalho de Conclusão de Curso (Bacharelado em Engenharia Ambiental e Sanitária) - Universidade Federal de Sergipe, São Cristóvão, Sergipe, 2019. SANTOS, G. G.; GRIEBELER, N. P.; DE OLIVEIRA, L. F. C. Chuvas intensas relacionadas à erosão hídrica. Revista Brasileira de Engenharia Agrícola e Ambiental, v. 14, n. 2, p. 115-123, 2010.
} 
SANTOS, A.R.; LOUZADA, F.L.R.O.; EUGENIO, F.C. ARCGIS 9.3 total: aplicações para dados espaciais. Alegre: CAUFES, 2010. 185p.

SANTOS, R. A.; MARTINS A. A.; NEVES J. P.; LEAL R. A. Geologia e Recursos Minerais do Estado de Sergipe. Texto Explicativo do Mapa Geológico do Estado de Sergipe. Brasília: CPRM, 1998, 156p.

SANTOS, L. A. N.; NASCIMENTO, P. S. R. Espacialização da suscetibilidade erosiva a partir da densidade de drenagem pelo interpolador Kernel. In: SIMPÓSIO BRASILEIRO DE SENSORIAMENTO REMOTO, 19., 2019, Santos. Anais... São José dos Campos: INPE, 2019, p. 27-30.

; BARROS, B. V. P. Espacialização da potencialidade erosiva por estimador Kernel na Bacia Hidrográfica do Rio Japaratuba (SE). In: ZUFFO, A. M. Engenharia sanitária e ambiental: tecnologias para a sustentabilidade. Ponta Grossa: Atena Editora, 2019. p. 123-131.

SÃO MIGUEL, A. E; MEDEIROS, R. B.; GOMES, W. M. Emprego do Sensoriamento Remoto e Sistema de Informação Geográfica na avaliação da fragilidade ambiental da bacia hidrográfica do Ribeirão São Pedro, Santa Rita do Pardo/MS. Cerrados, v. 16, n. 2, p. 3150, dez. 2018.

SCOLFORO, J.R.S.; OLIVEIRA, A.D.; CARVALHO, L.M.T. Zoneamento Ecológico Econômico do Estado de Minas Gerais - componentes geofísicos e bióticos. Lavras: Editora UFLA, 2008.

SEMARH. Secretária de Estado do Meio Ambiente e dos Recursos Hídricos. Atlas de Recursos Hídricos do Estado de Sergipe. Aracaju: SRH, 2013.

SILVA, A. B. Sistemas de informações georeferenciadas: conceitos e fundamentos. Campinas: Editora da Unicamp, 2003. 236p.
SILVA, K. Estimativa da variação temporal da eutrofização no Baixo São Francisco, a partir da utilização de índice Trix. 2018. 75f. Dissertação (Metrado em Geografia) - Universidade Federal de Alagoas, Maceió, 2018.

SILVA, R. M.; BELDERRAIN, M. C. N. Considerações sobre métodos de decisão multicritério. In: ENCONTRO DE INICIAÇÃO CIENTÍFICA E PÓS-GRADUAÇÃO DO ITA, 11., 2005, São José dos Campos. Anais... São José dos Campos: ITA, 2005. p. 1-7.

SILVA, C. A.; NUNES, F. P. Mapeamento de vulnerabilidade ambiental utilizando o método AHP: uma análise integrada para suporte à decisão no município de Pacoti/CE. In: SIMPÓSIO BRASILEIRO DE SENSORIAMENTO REMOTO, 14., 2009, Natal. Anais... Aracaju-SE: INPE, 2009. p. 5435-5442.

STEPHAN, A. M. Análise de processos erosivos superficiais por meio de ensaios de Inderbitzen. 2010, 165f. Tese (Doutorado em Engenharia Civil) Universidade Federal de Viçosa, Viçosa, Minas Gerais, 2010.

TRICART, J. Ecodinâmica. Rio de Janeiro: FIBGE/SUPREN, 1977. 97p.

WADT, P.G.S.; PEREIRA, R. C.; SOUZA, C. B. C.; ALVES, L. S. Práticas de conservação do solo e recuperação de áreas degradadas Rio Branco: Embrapa Acre, 2003. 912p.

WEILL, M. A. M.; PIRES NETO, A. G. Erosão e assoreamento. In: SANTOS, R. F. Vulnerabilidade ambiental - desastres naturais ou fenômenos induzidos? Brasília: MMA, 2007. p. 39-58.

WISCHMEIER, W. H; SMITH, D.D. Rainfall energy and its relationships to soil loss. Transactions of the American Geophysical Unio n, v. 39, n. 2, p. 285-291, 1958. 